\title{
PRIMARY AND SECONDARY APPRAISALS IN MEASURING RESILIENCE TO STRESS
}

\author{
Boris B. Velichkovsky \\ Moscow State University \\ Moscow
}

Measuring resilience to stress (or stress resistance) validly and reliably is an important theoretical and practical problem. Process-oriented stress theories assume that primary and secondary appraisals play an important role in determining the level of resilience. In the present study, a model of resilience based on the analysis of the interplay between primary and secondary appraisal processes is developed. Resilience is high if benign primary appraisals of taxing situations are accompanied by secondary appraisals of coping resources as being sufficient for controlling stressors. In an implementation of the model, the quality of primary appraisals is assessed through the assessment of anxiety, anger and depression, which characterize the most typical cognitive-emotional reactions to demanding situations. The assessment of secondary appraisals is restricted to the analysis of psychophysiological (functional) resources, which are involved in all forms of coping activities. The implementation of the model gives rise to a measure of resilience, which is shown to successfully predict the outcome of the stress process in a sample of Russian police officers.

Keywords: resilience, stress process, situation appraisal, psychophysiological resources, assessment, validity.

\section{The construct of resilience}

Resilience is one of the core constructs in contemporary stress research. Resilience is a broad term, which subsumes a number of conceptually related notions (for a recent review, see Earvolino-Ramirez, 2007). Historically, the first use of the term was in the developmental psychopathology, where it referred to the ability of the child to display normal psychological development despite negative "starting condi-

This study was supported by 08-08-00342a grant from Russian Humanitarian Scientific Foundation. 
tions", such as psychiatric disorder of a parent (Garmezy, et al., 1984). This line of research originated in a famous longitudinal study of the developmental patterns exhibited by over 500 "high-risk" children, in which it was shown that a substantial proportion of them grew up as well adapted adults (Werner, and Smith, 1982). Since then, numerous studies on kids and adolescents were performed with the aim to extract the defining characteristics of the "resilient" individual. Another important line of research is the study of resiliency in the elderly people (Kling, Seltzer, and Ryff, 1997; Ong, et al., 2006). In the older age, simple daily problems may accumulate becoming a source of chronic stress. Additionally, the probability of severe negative events (like death of a spouse) increases. Thus, the study of resilience in the elderly population concentrates on the mechanisms, which help to attenuate the negative effect of such acute and chronic stressors. Resiliency is also studied in the midlife (Bonanno, 2004). Here, again, it is the successful adaptation to traumatic experiences (for instance, a terrorist attack), which is being investigated in the first line. Finally, the term is used with adults meaning the ability to overcome "the stress of life" without developing psychiatric symptoms (Hjemdal, et al., 2006).

Common to all these approaches to resilience is "a sense of recovery and rebounding despite adversity and change" (Earvolino-Ramirez, 2007, p. 74). Indeed, an inspection of the literature suggests that the application of this notion should not be restricted to some specific age. On the contrary, it can be extended to mean a general ability of the individual to withstand adversity. Another point in extending the concept of resilience is to question the emphasis on major negative events (resilience "presupposes exposure to substantial adversity", Luthar, et al., 2000, p. 546), which is made in resilience research. The resistance to the negative influence of accumulated daily hassles seems to be at least equally important because of the much greater prevalence of the later. Interestingly, an extended discussion on the relative importance of major life events and daily hassles for the stress research had been held already (Dohrenwend, et al., 1984). It has been shown that the influence of major stressors is almost completely mediated by the effects of daily hassles (Wagner, Compass, and Howell, 1988). The development of the resilience concept thus parallels the development of the stress concept This is not surprising, given the close connection between both notions. Taking these considerations into account, resilience can be conceptu- alized as the ability to overcome short-term or chronic stress without deleterious effects of distress. This means that the resilience processes prevent stressors from having negative somatic, behavioral and psychological consequences, which the stressors would have if the resiliency processes were not active. Resilience is inversely related to stress vulnerability. In fact, these are two sides of exactly the same coin. Such an understanding of resilience is at least implicitly presented in the body of the stress literature (Lazarus, 1993; Kobasa, and Puccetti, 1983).

A recent tendency in the resilience research is worth mentioning. Resilience is now being conceptualized as a dynamic process (Earvolino-Ramirez, 2007; Luthar et al., 2000), and not as a trait (referred to as "resiliency"). This means that the outcome of the adaptation crucially depends on the characteristics of actual transactions of the individual and the world. Numerous protective factors, as they are identified in resilience research, could be understood as antecedents of resilience, but not as its immediate determinants. Under this perspective, it is not true that some individuals simply have not got the necessary personal or genetic prerequisites to adapt positively in the face of adversity and change. On the contrary, the study of the processes which leads to successful adaptation must be intensified, possibly yielding new interventions which address the unique strengths of the individual in order to help him in overcoming practically any difficulty. Closely connected to the conceptualization of resilience as a dynamic process is the understanding, that resilience is not absolute (Lazarus, 1990). Instead, resilience changes as a function of problem domain and as a function of time. The individual can exhibit weakness in response to some stressor and simultaneously be invulnerable to other stressors. This reflects the complex interplay of situational demands, resilience antecedents and resilience processes (Lazarus, and Folkman, 1987). Thus, resilience can be said to be "elastic" (Schumacher, et al., 2004). The elasticity of resilience is one of its major characteristics and a theory of resilience must take it into account explicitly. The problem of elasticity also gives rise to the important question of how stable personality traits are being instantiated in various resilience processes (Ong, et al., 2006).

Research on factors, promoting resilience (also called resistance or vulnerability factors, Holahan, and Moos, 1990, Kessler, Price, and Wortman, 1985) has flourished for many years. In classical resilience research, repeating lists of protective factors occur (Earvolino-Ramirez, 
2007). For resilient children, the following "resilience triad" (Richardson, 2002) is typically identified: a number of personality dispositions, such as easy temperament, existence of a supportive member in the family and social support. In stress research three classes of resilience factors are being distinguished, which overlap partly with the above mentioned triad (Holahan, and Moos, 1990). One class is made of various physiological and psychological dispositions. These include constitutional strength, hardiness, sense of coherence, learned resourcefulness dispositional optimism, self-efficacy, just to name a few. Coping strategies make another important class of resilience factors, with avoidance coping being the most inappropriate stress response (Proulx, et al., 1995). Various internal and external resources constitute the third class of resiliency factors, of which social support is the best known (Cohen, 2004). Intellectual capacities, social competence and financial assets are examples of resources which also can influence the outcome of the stress process. It can be seen, that the study of the resilience factors is primarily focused on the antecedents of the resilience process, and not on the process itself. Coping research constitutes one important exception to this rule. Another notable example of research on resilience factors, which is focused on the dynamic aspect of resilience, is the research on positive emotions and neutralization of negative effects of adversity (Tugade, and Fredrickson, 2004; Ong, et al., 2006).

Valid and reliable measurement of stress resilience level is an important objective in many practical domains. It is needed, for example, in personnel selection for high risk jobs. Another area of application is screening the general population for individuals, who are at risk of developing stress-induced somatic and psychological disorders. Because the measurement of stress resilience level is so important, a number of resilience measures were presented in the literature (Block, and Kremen, 1996; Connor, and Davidson, 2003; Friborg, et al., 2003; Wagnild, and Young, 1993). These measures assess either various personality dispositions associated with heightened resistance to stress or resources which protects the individual from being over-stressed. However, the development of resilience measures can be based on a quite different theoretical platform. This alternative approach is focused on understanding of resilience as an emergent property of an optimally or sub-optimally organized individual stress process. If resilience is being conceptualized in this way, then special attention must be devoted to the most crucial step of the evolving stress process - the process of appraisal. In the following, we present a description and empirical validation of a resilience measure which is based on the notions of stress process and cognitive appraisals.

\section{Stress process and resilience}

One of the major achievements in the stress research is the conceptualization of stress as a multidimensional process or transaction (Lazarus, 1990; Lazarus, and Folkman, 1984). According to this conceptualization, the process of stress goes through a sequence of stages. The first stage comprises the antecedents of the stress process - the personality, the environmental factors and, of course, the stressors. On the second stage the variables of interest are the variables of cognitive appraisal. When the situation and the ability to cope have been appraised in some particular way, the third stage begins. At this stage, various coping processes can be initiated, which constitutes the actual reaction to the stressors. The fourth stage is comprised of stress outcomes, which can be identified at various levels of personal organization. Built in this way, transactional stress theories constitutes a subset of interactional personality theories (Endler, and Parker, 1992; Fleeson, 2004). Proponents of transactional stress theories are interested not only in generalized behavioral tendencies, but in actual processes of perception and response selection, which links particular stressors to particular outcomes (Lazarus, and Folkman, 1987).

Where is resilience located in this model of the stress process? To answer this question, it helps to recall that resilience means the absence of deleterious effect of objectively existing stressors. Thus, resilience is high when the stressors are processed in such a way that no significant distress arises. In this respect, the notions of primary and secondary cognitive appraisals are crucial. Primary appraisal is concerned with the evaluation of how (potentially) harmful a particular situation is. Secondary appraisal is concerned with the evaluation of whether the individual possesses the resources to successfully face the demands of the situation. The well-known axiom of the stress research states that distress arises when the demands of the situation exceed the coping resources of the individual (Lazarus, 1990). Resilience is thus a dynamic characteristic of the stress process or, more specifically, of the appraisal 
process. Resilience emerges when there is either an extremely benign appraisal of the taxing situation, or an optimistic appraisal of coping resources, or both. In other words, resilience is present if appraisal processes signal that demands of the difficult situation are in balance with accessible coping resources. Seen is this light, resilience retains its already mentioned "elastic" nature. Thus, the appraisal processes and its outcome - the assessment of the demand-resources balance - are of fundamental importance for assessing the level of adaptation to psychological stress. Their close relationship with resilience has often been noted by researchers (Holahan, and Moos, 1990; Major, et al., 1998). Under these circumstances, the idea to measure resilience through the measurement of appraisal processes seems well justified.

We begin with considering the primary appraisals first. There are two approaches to assessing primary appraisals - cognitive and emotional (Lazarus, and Folkman, 1987). The cognitive approach is concerned with the stakes the individual has in a taxing situation. This approach is severely limited, due to the infinity of possible taxing situation and personal values. The second approach is concerned with measuring of the emotional reaction to the stressors. Emotional reactions of the individual inform us, whether the situation is somehow perceived as taxing without any reference to the content of the stressful encounter. Emotional reactions thus form a universal "code", which allow us to infer how the person interprets the situation. We propose that three cognitive-emotional experiential complexes can be used to assess the appraisal of a difficult situation: anxiety, anger and depression. It can be argued, that these complexes are related to both negative types of appraisals - threat and harm. The close relationship of anxiety to the threat appraisals is fairly obvious. Anger is a natural reaction in the case of harm, when the damage to some personally significant value is attributed to an external agent. Depression is another natural reaction to harm, in which the damage to a personally significant value is attributed to the inadequacies of the individual himself. In real-life situations, these types of appraisal can be mixed and, consequently, anxiety, anger and depression arise simultaneously (Hammen, and Compas, 1994). In sum, these three experiential complexes can be regarded as effective indicators of the negative appraisal of taxing situations.

Secondary appraisals crucially depend on various coping resources, which help the individual to overcome stressors. Assessing coping re- sources, similarly to the case of assessing the stress potential of a given situation, faces the problem of multiplicity of resources. That is, there are too many resources to be taken in consideration. This multiplicity forces the researcher to concentrate one some types of resources while neglecting other. One type of coping resources, which merit special attention, is comprised of functional resources. Under functional resources we understand psychophysiological resources, which are actualized by the individual when the progression of important activities is endangered (Leonova, 2003). A fundamental functional resource is ensuring an appropriate level of vigilance in performance of ongoing tasks. Without this, any activity is deemed to fail. Thus, the exhaustion of this specific type of resources marks a definite inability of the individual to cope with the incoming stressors. In the subsequent analysis, we will concentrate on this resource only, although other coping resources should be incorporated in more advanced models of resilience as well. The depletion of psychophysiological resources can be measured directly by the construct of fatigue (DeLuca, 2005). From the phenomenological point of view, fatigue is a subjective experience of a state, where there is simply not enough "power" to accomplish even important tasks.

\section{The model of resilience}

The following simplified model of resilience arises from the previous discussion. There is a lack of resilience, if a taxing situation produces heavy distress. This occurs when two conditions hold. First, the situation must be appraised as taxing independent of its objective content. Such an occasion is indicated by the rise in the indicators of anxiety and/or anger and/ or depression. Second, possible coping activities must be under-supplied with resources, of which energy supplies are the most basic ones. The lack of energy supply can be indicated by the rise of fatigue. When anxiety, anger, depression and fatigue are low, a high level of resilience can be inferred. If resilience is made dependent on the outcome of appraisal processes, it becomes clear that resilience cannot be absolute. Resilience level changes according to changes in stressors and in the resource supply of the individual. The variable nature of resilience gives rise to the question, how stable personal dispositions and transient states interact in producing stress reactions. We assume that the answer to this question can be sought for in the state-trait approach (Spielberger, 1972). 
The state-trait approach has close relationship to the interactional personality theories and, through this, to stress theories (Endler, 1997). In the process-oriented, interactional theories of stress the constructs of traits (dispositions) and states are given distinct functional roles (Lazarus, and Folkman, 1987). Dispositions are understood as antecedent variables, and states are understood as transactional variables. Antecedents create the context, in which the stress process takes place. The realization of the stress process is described in terms of transactional variables. The knowledge of dispositions allows, for example, making probabilistic predictions about the outcomes of appraisal processes for an individual. But it is the appraisal processes themselves, on which the level of the experienced distress depends. Dispositions predispose the person to some specific stress reaction and are instantiated in corresponding states, while simultaneously interacting with a host of other stress antecedents. Again, a backward relationship is also possible. If an individual experience a certain state often enough, this leads to the formation of a corresponding disposition. This conceptual scheme of the interaction between dispositions and states corresponds to the one adopted in the interactiona personality theories (Mischel, and Shoda, 1995; Pervin, 2001) and has a following consequence for the measuring of stress resilience level: Both dispositions and states must be assessed. Assessing dispositions gives us an idea of how probable the experience of a state is. Assessing states gives us an idea of how intense a state is being experienced. Combined, this information allows a thorough description of the stress process in general, and appraisal processes in particular. We will follow this lead in the development of a stress resilience measure as described below.

\section{Method}

\section{Participants}

The sample consisted of 542 Russian police officers, participating in a large scale study on professional stress and resilience. The data came from six regions of Russian Federation. 442 participants were males, reflecting the usual dominance of males in this occupation. Participants ranged in age from 19 to 51 year, with a mean age of 31.3 years $(\mathrm{SD}=6.6)$. The mean number of service years was 11.3 years $(\mathrm{SD}=6.7)$.

Using a sample of police officers in validating a stress resilience measure can be justified as follows. For this population, chronic influence of intensive stressors is typical. This increases the probability of finding objective evidence of ineffective adaptation to stress. Such evidence for example, health problems, - is often obscured in other populations, where psychological stress is not intensive enough to develop its full impact until only late in the lifespan. On the other hand, police officers constitute a relative homogenous population, in which the stress experienced is not confounded with the conditions of work and living.

\section{Resilience measure}

The assessment of the resilience level was based on a set of existing measures of resilience components (situational appraisals and functional resources). First block of measures included the measures of primary appraisals. The measures used for assessing anxiety, anger and depression were Russian versions of STAXI (Hanin, 1982), STAI (Leonova, and Spielberger, 2005) and STDI (Leonova, and Spielberger, 2005), respectively. All these measures consist of two scales, aimed at pinpointing the relevant characteristic in its situational (state) and dispositional (trait) aspect. The Russian versions are fully validated with the help of large samples. For all 6 scores, higher values indicate higher levels of anxiety, anger and depression.

The second block of measures included scales for assessment of functional resources, again taken in a situational and a dispositional aspect. As a disposition, the level of functional resources was measured with the help of a chronic fatigue scale (Leonova, and Kapitsa, 2005). The scale had been developed for the Russian population. The scale assesses the existence of the following chronic fatigue symptoms: physiological discomfort, reduced well-being, cognitive impairment, affective impairments, changes in motivation and social communication. Structurally, the measure consists of 36 questions asking for the existence of a specific symptom. Each of the questions can be answered on a scale of 0 to 2, reflecting the degree of participant's confidence in having a symptom (0 - symptom definitely absent, 2 - symptom definitely present). The answers are summed up to give a total score of chronic fatigue. Higher scores indicate stronger dispositional exhaustion of functional resources.

As a state, the level of functional resources is assessed through the construct of subjective comfort. To this end, a subjective comfort scale (Leonova, and Kapitsa, 2005) was used. The scale consists of 10 pairs of 
adjectives, which refer to typical positive and negative characteristics of subjective well-being (strong - weak, calm - agitated, etc). Every pair is rated on a 7 -point scale, with 1 corresponding to the maximally negative subjective experience, 7 corresponding to the maximally positive subjective experience, and 4 corresponding to a neutral subjective experience. The final score is obtained through summing up the scores for every pair of adjectives. Higher values of the final score indicate better well-being and higher level of functional resources. To make the scoring consistent, we transformed this score to an index of subjective discomfort. This was done by subtracting the subjective comfort score from the maximally possible score of 70. After this transformation, higher values indicated reduced well-being and stronger situational exhaustion of functional resources.

All the measures were transformed to standardized T-scores in order to excluded differences, which emerges from different metrics of the measures. Based on the T-scores, a composite resilience score (index of stress resilience, ISR) was computed. To this end, the measures (state anxiety, trait anxiety, state anger, trait anger, state depression, trait depression, chronic fatigue, subjective discomfort) were factor-analyzed with principal components extraction. A unique factor was obtained with factor weight of 6.2 , explaining $77.5 \%$ of the variance. The eigenvalues for other factors did not exceeded 0.6. One-factor solution was also supported by the analysis of the scree plot and by a parallel analysis, details of which are not given here. For the single extracted factor, factor loadings of all 8 measures were positive and high, and ranged from 0.951 (state anxiety) to 0.762 (subjective discomfort). This allowed us to interpret this factor as a Resilience factor. Subsequent to the factor extraction, factor scores were computed. According to the scoring used in the single measures, these scores reflect the level of vulnerability to psychological stress, which can hamper the interpretation of results. To overcome this inconvenience, values of ISR were computed by multiplying the factor scores by -1 . Thus obtained, the ISR is supposed to directly reflect the level of resilience, with higher level of ISR corresponding to higher level of resilience.

\section{Additional measures}

In order to validate ISR, a number of additional measures were obtained. These included measures of the adaptation to psychological stress and of experienced stress itself. The measures of adaptation were divided in measures of somatic, behavioral and psychological stress outcomes. Also, professional and life stressors were measured.

Somatic outcomes. Psychological stress can induce various chronic illnesses and also leads to increased probability of acute illness. The existence of chronic illness in participants was assessed with the item "Do you have some chronic illnesses?", which could be answered with either 'yes' or 'no'. Additionally, a list of typical stress-induced chronic illnesses (such as cardiovascular diseases, respiratory diseases etc.) was offered to the participants, which could indicate, whether they had a specific illness. From this data, the total number of chronic illnesses was computed. Proneness to acute illness was assessed with two item: "Have you been seriously ill in the last half a year?" and "Have you visited a doctor in the last half a year?". These items were also answered with either 'yes' or 'now'.

Behavioral outcomes. Psychological stress can lead to changes in behavioral patterns. Such changes can manifest themselves, for example, in unhealthy behaviors like drinking and smoking. These behavioral patterns constitute accessible forms of coping with stress, which are highly ineffective in the long-term and reduce resistance to future stressors. The intensity of smoking and drinking was assessed. For smoking, the assessment of intensity had 6 gradations ('not at all', 'occasionally', ' $1-2$ cigarettes a day', 'no more than 10 cigarettes a day', 'no more than 20 cigarettes a day', 'more than 20 cigarettes a day'). For drinking, the assessment of intensity had 5 gradations ('not at all', 'occasionally', 'no more than once a week', '2-3 times a week', 'every day'). The intensity was coded numerically for both behaviors ( 0 through 5 for smoking, 0 through 4 for drinking).

Psychological outcomes. Beside somatic and behavioral consequences, psychological stress can lead to various psychological changes. These include, among other, stable personality changes, of which type A personality and psychological burnout are probably the most known (Schabracq et al., 1996; Maslach, 1976). Type A personality was assessed with a Russian version of the S.D. Jenkins' type A scale (Jenkins, 1971), adapted in (Yazykova, and Zaitsev, 1990). Higher values of the score reflect stronger type A personality. Burnout was assessed by Russian burnout inventory (Vodopyanova, and Starchenkova, 2001), which is based on Maslach Burnout Inventory (Maslach, 1976). The burnout measure consists of three subscales (Emotional Exhaustion, Depersonalization and Reduction of Personal Achievements). As a whole, the inventory 
is made of 22 items. Participants rate the frequency, with which they experience the states described in the statements on a 7-point scale $(0-$ 'never', 7 - 'always'). One total score for every subscale of the inventory was obtained. Higher scores indicate higher level of burnout. Type A and burnout scores were transformed to T-scores.

Experienced stress. The assessment of the stress level was done with a Russian version of BMSII (Platt, and Richter, 1984), adapted in (Leonova, and Velichkovskaya, 2002). This questionnaire consists of four subscales, of which only the Stress subscale was used. The subscale measures the level of workplace stress. Stress scores were, as other measures, transformed to T-scores.

Professional and life stressors. The participants were given a list of professional stressors, where they could indicate, whether a particular stressor is presented in their professional lives. The stressors included: change of employment, having been laid off, promotion, serious conflict at the workplace, serious professional failure, financial instability of the organization, innovations in the organizations. The answers were coded numerically as 0 (stressor absent) and 1 (stressor present). The participants were also given a list of private stressors, where they could indicate, whether a particular stressor is presented in their private lives. The stressors included: moving, marriage, birth of a child, serious conflict in the family, divorce, serious illness or injury, death of a closely related person. The answers were coded numerically as 0 (stressor absent) and 1 (stressor present). Based on both measures, a total number of stressors was computed.

\section{Procedure}

The data collection was done in close cooperation with the Human Resources Department of Russian Ministry of Home Affairs. The questionnaires were printed in a single booklet. The booklets were sent centrally from the Human Resources Department of the Ministry to the regional departments of Home Affairs. In the regional departments, the survey was performed under the supervision of local human resources managers. Prior to the filling of the questionnaire, participants were told that their answers will be handled anonymously and will have no consequences for their further career. The filled questionnaires were sent back to the Human Resources Department, where the authors obtained them. Data analysis was performed with SPSS, version 13.

\section{Results}

The aim of the present study is to show sufficient construct validity of the proposed resilience measure. The results are presented in four sections. After giving the descriptive statistics, we show that the composite resilience index correlates in a predicted way with various measures of the adjustment to stress. Then we will analyze the relationship between ISR, experienced stress and presence of various stressors. Finally, we will study ISR as a moderator of the stressor-stress relationship.

\section{Descriptive statistics}

Table 1 presents the means, standard deviations, actual ranges or percent of 'yes'-responses for the measures used in the study.

Table 1

Descriptive statistics for the measures used in the study

\begin{tabular}{lcccc}
\hline \multicolumn{1}{c}{ Measure } & M & SD & $\begin{array}{c}\text { \% 'yes' } \\
\text { responses }\end{array}$ & $\begin{array}{c}\text { Actual } \\
\text { range }\end{array}$ \\
\hline $\begin{array}{l}\text { Resilience } \\
\text { State anxiety }\end{array}$ & 41.3 & 7.52 & - & $29.6-79.6$ \\
Trait anxiety & 40.9 & 7.18 & - & $26.7-71.7$ \\
State anger & 37.1 & 3.8 & - & $35.8-81$ \\
Trait anger & 43.9 & 7.22 & - & $32.4-80.9$ \\
State depression & 37.4 & 7.42 & - & $28.2-75.6$ \\
Trait depression & 37.7 & 6.96 & - & $27.6-68.7$ \\
Subjective discomfort & 38.6 & 10.36 & - & $19.6-76.1$ \\
Chronic fatigue & 33.8 & 8.48 & - & $49.6-86.2$ \\
Somatic conseq $\quad$ uences & & & & \\
Acute illness & - & - & $6 \%$ & - \\
Visiting a doctor & - & - & $25 \%$ & - \\
$\begin{array}{l}\text { Presence of chronic illnesses } \\
\text { Number of chronic illnesses }\end{array}$ & - & - & $19 \%$ & - \\
$\begin{array}{l}\text { Behavioral consequences } \\
\text { Intensity of smoking }\end{array}$ & 0.28 & 0.57 & - & $0-4$ \\
$\begin{array}{l}\text { Intensity of drinking } \\
\text { Psychological consequences }\end{array}$ & 1.83 & 1.76 & - & $0-5$ \\
Type A & 1.18 & 0.75 & - & $0-4$ \\
$\begin{array}{l}\text { Burnout/Emotional Exhaustion } \\
\text { Burnout/Depersonalization }\end{array}$ & 34.2 & 12.16 & & $6.6-70.7$ \\
Burnout/Reduction of achievements & 38.3 & 9.68 & - & $19.8-78.2$ \\
$\begin{array}{l}\text { Experienced stress } \\
\text { Number of stressors }\end{array}$ & 44.6 & 11.9 & - & $22.9-77.5$ \\
\hline & 43.8 & 16.0 & - & $19.6-125.3$ \\
& 0.78 & 4.24 & - & $35.0-56.8$ \\
& & & & $0-12$ \\
\hline
\end{tabular}


Components of the resilience measure. Comparing the results for the components of the resilience measure with existing norms reveals that in the studied sample dominate low levels of negative situation and resource appraisals. The only exception is trait anger, which reached moderate level. The components of resilience measure correlated highly with each other (rs from 0.21 to 0.64 , all ps $<0.001$ ), which justifies the factorization result mentioned above.

Stress outcomes. The prevalence of acute illness was relatively low with only $6 \%$ of the sample reporting having a serious illness within the last half a year. Still, a quarter of the sample reported having seen a doctor in this time period. Almost one-fifth of the sample has at least one chronic illness. The majority of the chronic ill has only one illness, and the total number of chronic illnesses never exceeds four. The majority of the sample smokes at moderate rates (no more than 1-2 cigarettes a day), although smoking showed substantial variability. The distribution of drinking intensity is skewed to the left, with most of the participants reporting drinking only occasionally. There still were participants who reported drinking more often than this. Low levels of both stress-induced personality deformation - type A personality and burnout - were found. The inspection of the ranges shows, however, that there are also individuals in the sample with very high scores of personality deformations.

Stress and stressors. According to published norms, low to moderate levels of stress at the workplace were found in the sample. For the majority of the sample, the total number of stressors had not exceeded 4 (the only case with 12 stressors was a clear exception).

On the whole, the sample can be characterized as experiencing moderate level of stress and demonstrating benign appraisal processes. The sample is well-adjusted to psychological stress and shows reasonable variation with respect to various stress outcomes.

\section{ISR and stress outcomes}

Somatic outcomes. We expected, that high values of ISR would lead to low level of stress-induced health problems. To show the relationship between ISR and somatic stress outcomes, a series of logistic regressions was computed. The first logistic regression contained the variable 'having a serious illness during the last half a year' as the dependent variable. Regressing it on ISR lead to a significant $\chi^{2}(\mathrm{df}=1)=231.8(\mathrm{p}<0.001)$. The loglikelihood value was equal to 447.5 . 50.3\% of the dependent vari- able's variance was explained according to Nagelkerkes- $\mathrm{R}^{2}$, indicating a good model fit. The regression coefficient was significant $(p<0.001)$ and equal to -2.74 . This means, that the probability of having a serious illness during the last half a year significantly decreases with large values of ISR. The second regression predicted the variable 'having seen a doctor during the last half a year' with ISR. A significant $\chi^{2}(\mathrm{df}=1)=118.0$ ( $\mathrm{p}<0.001)$ was obtained. The loglikelihood value was equal to 562.6. $28.5 \%$ of the dependent variable's variance was explained according to Nagelkerkes- $\mathrm{R}^{2}$, indicating a reasonable model fit. The regression coefficient was significant $(\mathrm{p}<0.001)$ and equal to -1.68 . This means, that the probability of having seen a doctor during the last half a year significantly decreases as ISR rises. The last equation regressed the variable 'having at least one chronic illness' on ISR. The regression lead to a significant $\chi^{2}(\mathrm{df}=1)=197.9(\mathrm{p}<0.001)$. The loglikelihood value was equal to 481.3 . $44.3 \%$ of the dependent variable's variance was explained according to Nagelkerkes- $\mathrm{R}^{2}$, indicating a good model fit. The regression coefficient was significant $(\mathrm{p}<0.001)$ and equal to -2.41 . This means, that the probability of having at least one chronic illness significantly increases as values of ISR falls. Additionally, the relationship between the intensity of chronic health impairments and ISR was studied. If ISR is a valid measure of stress resilience, there must be a negative association between the total number of chronic illnesses and ISR. As the total number of chronic illnesses is not normally distributed, a Spearmen correlation coefficient was computed, which was found to be negative and significant (rho $=-0.26, \mathrm{p}<0.001)$.

Behavioral outcomes. Two inadequate behavioral coping strategies smoking and consuming alcohol - were assessed in our study as indicators of behavioral changes induced by chronic psychological stress. As in the case of somatic stress outcomes, we tried to show that there is a negative association between ISR and intensity of these behaviors. To this end, Spearmen correlation coefficients were computed for ISR and both variables in question. For drinking, this resulted in a negative and significant correlation (rho $=-0.34, \mathrm{p}<0.001$ ). For smoking, a significant negative correlation was again found ( $\mathrm{rho}=-0.11, \mathrm{p}<0.01$ ), which, however, was substantially smaller in the magnitude.

Psychological outcomes. To identify the relationship between ISR and psychological outcomes of stress, ISR was correlated with the index of Type A personality and all three components of psychological burnout. 
Again, we expect that there will be a negative association between the level of stress resilience as measured by ISR and intensity of stress-induced personality deformations. This expectation could be confirmed in all cases. For Type A personality, a significant negative correlation was obtained (Pearson's $\mathrm{r}=-0.34, \mathrm{p}<0.001$ ). The same was true for burnout scales (emotional exhaustion $-\mathrm{r}=-0.81, \mathrm{p}<0.001$; depersonalization $-\mathrm{r}$ $=-0.45, \mathrm{p}<0.001$; reduction of achievements $-\mathrm{r}=-0.55, \mathrm{p}<0.001)$.

\section{ISR, stress and stress spiral}

A valid measure of stress resilience could naturally be expected to correlate negatively with the level of experienced stress. Indeed, stress resilience implies low stress by definition. To test this supposed relationship, a Pearson correlation coefficient was computed for ISR and the Stress scale. The coefficient was significant and negative with $r=-0,63$ $(\mathrm{p}<0.001)$, indicating a strong inverse connection between both variables. This connection, although in line with the theoretical expectations, gives rise to an important question. One is tempted to explain this correlation by the fact, that ISR is confounded with the Stress scale. Indeed, ISR comprises such components as anxiety, anger and depression, which can be seen as prototypical indicators of stress. Below, we will show that contrary to this possible explanation, ISR is not a measure of stress. To this end we will investigate some data on the so-called "stress spiral".

The identification of dependent and independent variables in the stressful encounter is considerably complicated by the existence of reciprocal dependences between the stages of the stress process. This is true, for example, for the stressors. Being the independent variables per $s e$, they can be influenced by the specifics of the previous stress transactions. It is well known, that the intensive future stress can be predicted on the basis of acute stress. This relationship holds, because acute stress lowers stress resilience and hampers the individual in preventing new stressors from occurring. Thus, stress can be said to generate more stress, which in turn generate even more stress (stress spiral). Empirically, stress spiral can manifest itself in the existence of significant negative correlation between the level of stress resilience and the number of stressors (lowered resilience leading to generating more stressors). The real situation is, however, more complex. Two types of stressors can be distinguished, which interact with stress resilience in different ways exogenous and endogenous stressors.
Exogenous stressors emerge independent of individual attitudes, efforts and failures. They can be conceived of as hardly preventable "acts of destiny", which overtake the individual in the course of his life. A death of a close relative is a typical example of exogenous stressor. Being independent of the actions of the individual, exogenous stressors are also independent of his stress resilience level. Consequently, exogenous stressors don't play an influential role in the unfolding of stress spirals, although they can clearly initiate such spirals. The contrary is true for endogenous stressors. A typical example of an endogenous stressor is divorce. The stressors of this type are at least partly brought into existence by the intentions and doings of the individual. They can be conceived of as (partly) stemming from the adaptational inadequacy of the individual herself. Thus, endogenous stressors are the real "driving force" of stress spirals, being generated at every new iteration of the spiral with accelerating rates. The differentiation of exogenous and endogenous stressors allows making specific prediction about their relationship with stress resilience measures. A valid stress resilience measure should display no relation to the number of exogenous stressors, but it should be negatively related to the number of endogenously stressors.

In this study, exogenous and endogenous stressors were identified by consulting experts. Two psychologists from Moscow State University, holding a doctoral degree in psychology and not acquainted with the study, were independently asked to divide a list of stressors into exogenous and endogenous stressors. The list was comprised of private and professional stressors, described in the Methods section. Exogenous stressors were defined as "being largely independent of individual's adaptational inadequacy", whereas endogenous stressors were defined as "being to some extent dependable on individual's adaptational inadequacy". Experts gave highly consistent results, with their opinions differing only on one stressor (having been laid off). The inconsistency was settled during a personal meeting of the experts. Nine stressors were identified as exogenous (change of employment, promotion, financial instability of the organization, innovation in the organization, moving, marriage, birth of a child, serious illness or injury, death of a closely related person). Five endogenous stressors were identified (having been laid off, serious conflict at the workplace, serious professional failure, serious conflict in the family, divorce). Subsequent to the identification of stressor types, the total number of exogenous and endogenous stressors 
was computed for every participant in the study. These totals were then correlated (Spearmen's rank correlation) with ISR. Confirming the prediction, ISR was found to correlate highly significantly and negatively with the number of endogenous stressors (rho $=-0.31, \mathrm{p}<0.001)$. ISR did not correlate significantly with the number of exogenous stressors $($ rho $=-0.07, \mathrm{p}>0.05)$.

\section{ISR and buffering function of resilience}

At the core of the resilience concept lays the notion of its buffering function. High resilience prevents ("buffers") negative stress effects from occurring even in the presence of stressors. If the stressors are very intensive, high resilience still attenuates their impact on the somatic and psychological well-being. If resilience level is low, nothing prevents stressors from exerting their influence on the individual. A valid measure of stress resilience must reflect this buffering function. Technically, it must be shown, that a resilience measure moderates the relationship between the objective intensity of stress and the intensity of various stress consequences. We describe this relationship as the stressor-stress relationship. The most well-known instance of stressor-stress relationship is the stress-illness relationship (Holmes, and Masuda, 1974), manifesting itself in a positive correlation between the number of stressors and the probability of acute illness. Of course, we should not limit ourselves with considering only somatic consequences of stress. Stressor-stress relationships can be identified on every level of the individual organization. Here, we consider somatic, psychological and behavioral levels.

The moderating effect of a resilience variable is shown, if stressorstress relationship holds in a sample with low resilience values, and disappears in a sample with high resilience values. To this end, we mediansplitted our sample on ISR. As can be seen from Table 2, moderating effect of ISR is consistently observed throughout many measures of adaptation. For example, there is a significant positive association between the total number of stressors, experienced in the last half a year, and the total number of chronic illnesses in the group of non-resilient participants (Spearmen's rho $=0.16, \mathrm{p}<0.05$ ). The presence of this link (which is highly obscured by other factors) is contrasted with the absence of the same link in the sample of resilient individuals (Spearmen's rho $=0.09, \mathrm{p}>0.05)$. More markedly, the same result is found for the relation between the intensity of stress and the intensity of various per-

The relationship between intensity of stress and various stress outcomes for groups of resilient and non-resilient individuals

\begin{tabular}{|c|c|c|c|c|c|c|}
\hline \multirow{2}{*}{ Stress outcome } & \multicolumn{2}{|c|}{ Total sample } & \multicolumn{2}{|c|}{ Resilient } & \multicolumn{2}{|c|}{ Non-resilient } \\
\hline & $\mathrm{r}$ & $\alpha$ & $\mathrm{r}$ & $\alpha$ & $\mathrm{r}$ & $\alpha$ \\
\hline $\begin{array}{l}\text { Chronic illnesses } \\
\text { Psychological } \\
\text { consequences }\end{array}$ & 0.094 & $<0.05$ & 0.091 & $>0.05$ & 0.159 & $<0.05$ \\
\hline Type A personality & 0.364 & $<0.001$ & 0.031 & $>0.05$ & 0.432 & $<0.001$ \\
\hline $\begin{array}{l}\text { Burnout/Emotional } \\
\text { Exhaustion }\end{array}$ & 0.470 & $<0.001$ & -0.057 & $>0.05$ & 0.713 & $<0.001$ \\
\hline $\begin{array}{l}\text { Burnout/Depersona- } \\
\text { lization }\end{array}$ & 0.498 & $<0.001$ & -0.022 & $>0.05$ & 0.716 & $<0.001$ \\
\hline $\begin{array}{l}\text { Burnout/Reduction } \\
\text { of Achievements }\end{array}$ & 0.425 & $<0.001$ & -0.006 & $>0.05$ & 0.581 & $<0.001$ \\
\hline $\begin{array}{l}\text { Behavioral } \\
\text { consequences }\end{array}$ & & & & & & \\
\hline Intensity of drinking & 0.245 & $<0.001$ & 0.016 & $>0.05$ & 0.375 & $<0.001$ \\
\hline Intensity of smoking & 0.178 & $<0.001$ & 0.087 & $>0.05$ & 0.273 & $<0.001$ \\
\hline
\end{tabular}

sonality deformations (for non-resilient participants, all rhos are significant and positive with values no lower than 0.43 , all ps $<0.001$; for resilient participants, all rhos are not significant and don't exceed 0.06 in absolute values). The same pattern is again observed for behavioral stress consequences like the intensity of smoking and the intensity of drinking (for non-resilient participants, rhos are no less than 0.27 , ps $<$ 0.001; for resilient participants rhos don't exceed 0.09, ps > 0.05).

\section{Discussion and conclusions}

In the present study, a resilience measure was derived and construct validated. The measure is sensitive to the balance between negative appraisals of the taxing situation and accessibility of functional coping resources. The measure has a multidimensional structure and includes scales for measuring anxiety, anger, depression and the level of functional resources. The measure also explicitly incorporates the distinction between states and traits. Thus, the measure reflects in a simplified way the complex interplay between the personality antecedents of the stress process and the states, which constitutes the stress transaction. To 
test the construct validity of the measure, a composite resilience index, ISR, was derived after factorization of the measure's subscales. A number of predictions about the behavior of the ISR were subsequently tested, ranging from rather general to very specific. We found that each of the tests confirmed the hypothesis that ISR is a valid indicator of stress resilience.

We first tested, whether higher levels of resilience as measured by ISR were associated with better adaptational outcomes. This prediction was confirmed for somatic, behavioral and psychological stress consequences. The probability of having at least one chronic illness or having an acute illness recently decreases sharply as ISR rises. The total number of chronic illnesses is also less when ISR is high. For inadequate behavioral coping strategies ("bad habits"), which are important indicators of failed adaptation to stress, the same pattern was observed. The intensity of smoking and drinking is less for participants with high ISR values. This is also true for the intensity of two typical stress-induced personality deformations - type A personality and psychological burnout. Thus, for various levels of individual organization, ISR is associated in predicted way with the quality of the stress outcome.

We also tested for the association between ISR and experienced stress levels. As predicted, higher ISR values were related to less intensive distress. In conjunction with the previous result, this pattern in the data is very important for testing the construct validity of ISR. Indeed, heightened stress resilience simply means experiencing less distress, which in turn leads to less manifest consequences of stress. There is one possible objection to this reasoning, however. ISR can be regarded as being simply an equivalent of the experienced stress level. This can be caused, for example, by the inclusion of anxiety and depression scales in the ISR. Anxiety and depression are the prototypical emotional responses implied by psychological distress. We tried to disentangle ISR from experienced distress by performing a more sophisticated analysis based on the phenomenon of the stress spiral. The notion of the stress spiral is being extensively elaborated in the conservation of resources theory (Hobfoll, 2001) under the name of loss spiral. It is shown in the conservation of resources theory, that the loss of various resources (for example, personal resources like self-esteem), subjectively experienced as distress, leads to further loss of other resources, and the rate of this process is constantly accelerating. We identified two types of stressors, which play different roles in the unfolding of the stress spiral. Exogenous stressors are independent of stress resilience level, whereas endogenous stressors are at least partly dependant on it. Interestingly, there is an extremely similar distinction between "independent" and "dependent" stressors in cognitive theories of depression (Hankin, and Abramson, 2001). The number of endogenous stressors lawfully increases if stress resilience is low, but the emergence of new exogenous stressors is due to chance. Confirming this expectation, we found that ISR is negatively correlated with the number of endogenous stressors and is not related to the number of exogenous stressors. We would like to note, that if ISR were an (inverted) measure of distress, it would correlate significantly with both types of stressors.

In another test of construct validity, ISR was shown to moderate the relationship between the intensity of objective stress and the severity of negative stress consequences (the stressor-stress relationship). Such moderation would mean that high level of resilience (as indicated by ISR) prevent negative effects of stress from occurring. The moderating effect was again in the predicted direction. In the group with high ISR, no stressor-stress relationship was found. In the group with low ISR, this relationship was highly significant. The unequivocality of this result is in some respect astonishing. For example, the moderating effect of ISR was registered for the relationship between the number of stressors and the number of chronic illnesses. The participants were asked to report only such stressors, which occurred to them half a year before the study. Thus, the link between both variables should be barely observable, being obscured by many other influential factors. Still, the link is clearly present in the group with low resilience and absent in the group with high resilience. On the whole, the behavior of the proposed resilience measure was found to be as predicted by current resilience theories in a variety of domains. This means that the measure can be used to assess resilience levels without validity concerns.

Valid and reliable resilience measurement is of great importance for both theoretical and practical reasons. Building and validating resilience scales sheds light on resilience as a complex, integrative property of the personality. It helps to identify components of resilience and their interplay, thus promoting a more thorough understanding of the construct. Along with this importance for theoretical research, having a rich repertoire of resilience measures is of significant practical inter- 
est. Identifying individuals with low resilience levels before they develop pronounced deficits of somatic and mental health is an obvious and valuable goal of resilience measurement. On the basis of such timely resilience measurement, appropriate preventive and corrective procedures can be initiated. This is especially important in the context of work and life settings, which are associated with high exposure to psychosocia stressors. To this end, a composite index of resilience can well be used. The analysis of the various components of resilience, on the other hand, can help to identify deficits in the workings of psychological regulatory systems, which is responsible for producing resilient outcomes. If the origins of these deficits are known, fine-tuned interventions can be implemented, which restore the individual's capacity to overcome stressors. Thus, building resilience measures means effectively assisting practical psychologists in reducing the suffering caused by the omnipresent stressors of the modern life.

\section{References}

Block, J., and Kremen, A.M. (1996). IQ and ego-resiliency: Conceptual and empirical connections and separateness. Journal of Personality and Social Psychology, 70. P. 349-361.

Bonanno, G.A. (2004). Loss, trauma, and human resilience: Have we underestimated the human capacity to thrive after extremely aversive events? American Psychologist, 59. P. 20-28.

Cohen, S. (2004). Social relationships and health. American Psychologist, 59, 8. P. 676-684.

Connor, K.M., and Davidson, J.R.T. (2003). Development of a new resilience scale: The Connor-Davidson Resilience Scale (CD-RISC). Depression and Anxiety, 18. P. 76-82. DeLuca, J. (ed.) (2005). Fatigue as a Window to the Brain. Cambridge; MA, MIT Press. Dohrenwend, B.S., et al. (1984). Symptoms, hassles, social supports and life events: The problem of confounded measures. Journal of Abnormal Psychology, 93. P. 222-230.

Earvolino-Ramirez, R.N. (2007). Resilience: A concept analysis. Nursing Forum, 42, 2. P. 73-82.

Endler, N.S. (1997). Stress, anxiety, coping: The multidimensional interaction model. Canadian Psychology, 38. P. 136-153.

Endler, N.S., and Parker, J.D. (1992). Interactionism revisited: Reflections on the continuing crisis in the personality area. European Journal of Personality, 6. P. 177-198

Fleeson, W. (2004). Moving personality beyond the person-situation debate. Current Directions in Psychological Science, 13. P. 83-87.
Friborg, O., et al. (2003). A new rating scale for adult resilience: what are the central protective resources behind healthy adjustment? International Journal of Methods in Psychiatric Research, 12, 2. P. 65-76.

Garmezy, N. (1984). The study of stress and competency in children: A building block for developmental psychopathology. Child Development, 55. P. 97-111.

Hammen, C., and Compas, B.E. (1994). Unmasking unmasked depression in children and adolescents: The problem of comorbidity. Clinical Psychology Review, 14. P. 585-603.

Hanin, Ju.L. (1982). Adaptatsiya shkaly lichnostnoy sorevnovatel'noy trevozhnosti [Adaptation of a trait competition anxiety scale]. Voprosy Psikhologii, 3. P. 136-141.

Hankin, B.L., and Abramson, L.Y. (2001). Development of gender differences in depression: An elaborated cognitive vulnerabilities-transactional stress model. Psychological Bulletin, 127. P. 773-796.

Hjemdal, O., et al. (2006). Resilience predicting psychiatric symptoms: A prospective study of protective factors and their role in adjustment to stressful life events. Clinical Psychology and Psychtherapy, 13. P. 194-201.

Hobfoll, S.E. (2001). The influence of culture, community, and the nested-self in the stress process: Advancing Conservation of Resources Theory. Applied Psychology: An International Review, 50. P. 337-421.

Holahan, C.J., and Moos, R.H. (1990). Life stressors, resistance factors, and improved psychological functioning: An extension of the stress resistance paradigm. Journal of Personality and Social Psychology, 58. P. 909-917.

Kessler, R.C., Price, R.H., and Wortman, C.B. (1985). Social factors in psychopathology: Stress, social support, and coping processes. Annual Review of Psychology, 36. P. 531-572.

Kling, K.C., Seltzer, M.M., and Ryff, C.D. (1997). Distinctive late-life challenges: Implications for coping and well-being. Psychology and Aging, 12. P. 288-295.

Kobasa, S.C., and Puccetti, M.C. (1983). Personality and social resources in stressresistance. Journal of Personality and Social Psychology, 45. P. 839-850.

Lazarus, R.S. (1990). Theory-based stress measurement. Psychological Inquiry, 1. P. 3-13.

Lazarus, R.S. (1993). From psychological stress to the emotions: A history of changing outlooks. Annual Review of Psychology, 44. P. 1-22.

Lazarus, R.S., and Folkman, S. (1984). Stress, appraisal, and coping. New York: Springer.

Lazarus, R.S., and Folkman, S. (1987). Transactional theory and research on emotions and coping. European Journal of Personality, 1. P. 141-169.

Leonova, A.B. (2003). Functional status and regulatory process in stress management. In G.R.L. Hockey, A.W.K. Gaillard, O. Burov (eds.). Operator Functional State. Amsterdam: IOS Press. P. 36-52. 
Leonova, A.B., and Kapitsa, M.S. (2005). Metody subektivnoy otsenki funktsional'nyh sostoyaniy cheloveka [Subjective assessment of human functional states]. In Ju.K. Strelkov (ed.) Praktikum po inzhenernoy psihologii i ergonomike [Practicum in engineering psychology and ergonomics]. Moskva: Academia. P. 136-167.

Leonova, A.B., and Spielberger, Ch.D. (eds.) (2005). Diagnostika emotsiy i stressa: novye psihodiagnosticheskie metodiki [Diagnostics of stress and emotions: New psychodiagnostic measures]. Moskva: Rossijskaya Akademiya Medicinskikh Nauk.

Leonova, A.B., and Velichkovskaya, S.B. (2002). Differentsial'naya diagnostika sostoyaniy snizhennoy rabotospsobnosti [Differential diagnostics of reduced work capacity]. In A.O. Prohorov (ed.) Psihologiya psihicheskih sostoyaniy [Psychology of mental states]. Kazan: Tsenter Innovatsionnyh Tehnologii. P. 326-343.

Luthar, S.S., Cicchetti, D, and Becker, B. (2000). The construct of resilience:A critical evaluation and guidelines for future work. Child Development, 27, 3. P. 543-562.

Major, B., et al. (1998). Personal resilience, cognitive appraisals, and coping: An integrative model of adjustment to abortion. Journal of Personality and Social Psychology, 74, 3. P. 735-752.

Maslach, C. (1976). Burned-out. Human Behavior, 5. P. 16-22.

Mischel, W., and Shoda, Y. (1995). A cognitive-affective system theory of personality: Reconceptualizing situations, dispositions, dynamics and invariance in personality structure. Psychological Review, 107. P. 246-268.

Ong, A.D., et al. (2006). Psychological resilience, positive emotions, and successful adaptation to stress in later life. Journal of Personality and Social Psychology, 91. P. 730-749

Pervin, L.A. (2001). A dynamic system approach to personality. European Psychologist, 6. P. 172-176

Proulx, J., et al. (1995). Coping strategies as predictors of distress in survivors of single and multiple sexual victimization and nonvictimized controls. Journal of Applied Social Psychology, 25. P. 1464-1483.

Richardson, G.E. (2002). The metatheory of resilience and resiliency. Journal of Clinical Psychology, 58. P. 307-321.

Schabracq, M.J., et al. (eds.) (1996). Handbook of work and health psychology. Chichester: Wiley.

Schumacher, J., et al. (2005). Die Resilienzskala - Ein Fragebogen zur Erfassung der psychischen Widerstandsfähigkeit als Personenmerkmal. Zeitschrift für Klinische Psychologie, Psychiatrie und Psychotherapie, 53. P. 16-39.

Spielberger, C.D. (1972). Anxiety as an emotional state. In C.D. Spielberger (ed.) Anxiety: Current trends in theory and research, 1. New York: Academic Press. P. 23-49.

Tugade, M.M., and Fredrickson, B.L. (2004). Resilient individuals use positive emotions to bounce back from negative emotional experiences. Journal of Personality and Social Psychology, 86. P. 320-333.
Vodopyanova, N.E., and Starchenkova, E.S. (2005). Sindrom vygoraniya: diagnostika i profilaktika [Burnout syndrom; diagnostics and prevention]. Sankt-Peterburg: Piter.

Wagnild, G.M., and Young, H.M. (1993). Development and psychometric evaluation of the Resilience Scale. Journal of Nursing Measurement, 1. P. 165-178.

Wagner, B.M., Compas, B.E., and Howell, D.C. (1988). Daily and major life events: A test of an integrative model of psychosocial stress. American Journal of Community Psychology, 16. P. 189-205.

Werner, E.E., and Smith, R.S. (1982). Vulnerable but invincible. A longitudinal study of resilient children and youth. New York: McGraw-Hill.

Yazykova, T.A., and Zaitsev, V.P. (1990). Tip A: problemy izucheniya i psihologicheskaya korrektsiya [Type A behavior: Research problems and psychological correction]. Psihologicheskii zhurnal, 11, 5. P. 56-60. 